[0212-7199 (2007) 24: 4; pp 177-178] ANALES DE MEDICINA INTERNA Copyright (C) 2007 ARAN EDICIONES, S.L.

AN. MED. InTERnA (Madrid) Vol. 24, N. ${ }^{\circ}$ 4, pp. 177-178, 2007

\title{
Enfermedad oportunista poco frecuente en paciente con lupus eritematoso sistémico con tratamiento inmunosupresor
}

\author{
J. PÉREZ SILVESTRE, C. CAMPOS FERNÁNDEZ, J. CALVO CATALÁ, \\ M. I. GONZÁLEZ CRUZ, A. BAIXAULI RUBIO, D. PASTOR CUBILLO
}

Sección de Reumatología y Metabolismo Óseo. Servicio de Medicina Interna. Hospital

General Universitario. Valencia

UNFREQUENTLY OPPORTUNISTIC INFECTION IN LUPUS ERYTHEMATOSUS WITH INMUNOSUPPRESIVE TREATMENT

\section{RESUMEN}

Presentamos un caso de lupus eritematoso sistémico complicado con pancitopenia y leishmaniasis visceral ocurrido en España. A propósito del mismo, realizamos una revisión bibliográfica sobre infecciones oportunistas en el lupus eritematoso sistémico. La leishmaniasis es un grupo de enfermedades causadas por el protozoo Leishmania, endémica en la cuenca mediterránea y de carácter oportunista y emergente en pacientes inmunodeprimidos. El uso de inmunosupresores en el tratamiento del lupus eritematoso sistémico induce modificaciones en la defensa natural, aumentando el riesgo de aparición de leishmaniasis visceral en zonas endémicas.

PALABRAS CLAVE: Leishmaniasis. Lupus Eritematoso Sistémico. Inmnunosupresores.
ABSTRACT

We present a case of systemic lupus erythematosus complicated by pancytopenia and visceral leishmaniasis in Spain. The literature on opportunistic infection in lupus erythematosus is reviewed.

Leishmaniasis is a group of infections caused by the protozoa Leishmania, which is endemic in the Mediterranean basin. These opportunistic infections are an emerging entity in immunosuppressed patients. The use of immunosuppressive treatment in systemic lupus erythematosus modifies natural defense patterns and increases the risk of visceral leishmaniasis in endemic areas.

KEY WORDS: Leishmaniasis. Systemic lupus erythematosus. Immunosuppressive.

Pérez Silvestre J, Campos Fernández C, Calvo Catalá J, González Cruz, MI, Baixauli Rubio A, Pastor Cubillo D. Enfermedad oportunista oco frecuente en paciente con Lupus Eritematoso Sistémico con tratamiento inmunosupresor. An Med Interna (Madrid) 2007; 24: 177-178.

\section{INTRODUCCIÓN}

Los pacientes afectos de lupus eritematoso sistémico tienen un mayor riesgo de desarrollar infecciones. Por una parte, por la alteración en la inmunidad producida por el uso de fármacos inmunosupresores y por otra, por la disfunción inmunológica que genera esta enfermedad. Presentamos el caso de un paciente con LES en tratamiento con corticoides, los cuales alteran la inmunidad humoral y condicionan una disminución de la resistencia frente a bacterias, virus, protozoos y hongos.

\section{CASO APORTADO}

Mujer de 32 años, diagnosticada de LES y síndrome antifosfolípido hace 6 años, controlada en consultas externas de Reumatología, en tratamiento con prednisona (15 mg al día), AAS (100 mg día), calcio ( $1 \mathrm{~g})$, vitamina D (800 u) y omeprazol (20 mg al día). Refiere fiebre $\left(40^{\circ} \mathrm{C}\right)$ de predominio vespertino, de una semana de evolución, sin otra sintomatología acompañante. En la exploración física sólo llama la atención hepatoesplenomegalia, sin adenopatías palpables. En cuanto a las exploraciones complementarias hemocultivos, urinocultivo, mantoux son negativos; Eco-Dopler y radiografía de tórax, dentro de la normalidad; TAC toraco-abdominal normal, salvo hepatoesplenomegalia sin lesiones focales aparentes. En la analítica Hb 6,7, leucocitos 1.000 (400 neutrófilos, 500 linfocitos), plaquetas 60.000 , ANA 1/1.280, antiDNA 42,3, factor reumatoide 176, PCR 11,9, C3 122/C4 11,2, proteinograma (gammaglobulina 44,2) y serologías normales. Ante posible brote de LES, se decide transfusión de dos concentrados de hematíes, inyecciones de C-GSF diarias, bolos de $1 \mathrm{~g}$ de metilprednisolona durante tres días, y amikazina y ceftazidima como tratamiento empírico de neutropenia. Tras cuatro días con el tratamiento descrito, se mantiene fiebre de $40{ }^{\circ} \mathrm{C}$, con valores analíticos semejantes:en nueva analítica $\mathrm{Hb} 8,5$, leucocitos 1.000 (400 neutrófilos, 500 linfocitos), plaquetas 32.000 , pensando que el cuadro no se corresponde con un brote de la enfermedad. Se decide 
realizar punción esternal, objetivando abundantes hemoparásitos del género Leishmania,confirmando la sospecha diagnóstica, iniciamos tratamiento con anfotericina B liposomal $200 \mathrm{mg}$ al día durante 5 días, quedando afebril el segundo día. Analítica de control a los 10 días de tratamiento: con $\mathrm{Hb} 11$, leucocitos 2600 (1.700 neutrófilos) y plaquetas 97.000 al alta.

\section{DISCUSIÓN}

La leishmaniasis visceral o kala-azar, es un grupo de enfermedades causadas por protozoos de la familia Trypanosomatidae, endémica en la cuenca mediterránea y de carácter oportunista y emergente en pacientes inmunodeprimidos. Existen dos formas de presentación clásica, visceral o kala-azar producida por L. Infantum (Levante), L. Donovani y L. Chagasi, y forma cutánea del Viejo Mundo causada por L. Tropica, L. Major $(1,2)$.

En nuestro país es de transmisión rural y periurbana, realizando su ciclo en un huésped invertebrado (flebotómo, de la familia Psychodidade), que transmite la enfermedad a un vertebrado, perro (reservorio principal) y hombre, afectando al sistema monocito-macrófago con su forma amastigote. La defensa natural ante Leishmania se realiza a través de la activación de la respuesta linfocitaria Th1, que a su vez activa los macrófagos; la Leishmania produce aumento de expresión de IL-10, citosina asociada a Th2, que inhibe la proliferación y funcionamiento de Th1; que asociada a la administración de inmunosupresores incrementará el riesgo de enfermedad parasitaria, sobretodo en zonas endémicas $(3,4)$.

El período de incubación es variable (días/meses); siendo su clínica más característica: fiebre alta, astenia, anorexia y hepatoesplenomegalia; con unos datos analíticos casi constan- tes:asociado a leucopenia, anemia, trombopenia, hipergammaglobulinemia, factor reumatoideo positivo y alteración de enzimas hepáticas. Sus órganos diana son bazo, hígado y médula ósea.

El diagnóstico debe sospecharse con la clínica y confirmarse con la detección de amastigotes con su núcleo y cinetoplasto, mediante tinción con Giemsa en la biopsia de bazo (la más sensible), aunque se utiliza frecuentemente la médula ósea por el riesgo de hemorragia, si la punción se realiza en bazo.

El tratamiento de elección son los antimoniales pentavalentes. En Europa se utiliza meglutamina a dosis de 20 $\mathrm{mg} / \mathrm{kg} /$ día durante 20 días, que puede asociarse a Interferón Gamma para reducir los días de tratamiento. La alternativa es anfotericina B liposomal $200 \mathrm{mg} /$ día/5 días, que fue el tratamiento usado en nuestro caso, sobre todo por la comodidad del tratamiento. Existen descritos casos de leishmaniasis cutánea tratada con fluconazol (5).

\section{CONCLUSIONES}

Existe una escasa casuística en relación a infección de Leishmania en pacientes con LES, encontrándose un único caso descrito en la bibliografía revisada (6).

En nuestro caso, por ser la cuenca mediterránea una zona endémica, estamos obligados a descartar una infección por Leishamnia en un paciente con fiebre y LES, a pesar de ser ésta una manifestación frecuente de la enfermedad. La modificación de los mecanismos de defensa natural en el LES conlleva el incremento del riesgo de enfermedades infecciosas. Si a esto asociamos la terapia inmunosupresora de fondo aumentará la incidencia y gravedad de las infecciones oportunistas (6-8).

\section{Bibliografía}

1. Katz KC, Wamsley S1, Mc Leod Ag, Keystone JS, Detsky AS. Whe are you from? N Engl J Med 2002; 346: 764-7.

2. Roberts LJ, Handman E, Foote SJ. Leishmaniasis. BMJ 2000; 321: 801-4.

3. Gladman DD, Hussain F, Ibañez D, Urowitz MB. The nature and outcome of infection in systemic lupus erythematosus. Lupus 2002; 11: 234-9.

4. Smith DS, Relman DA. Leishmania and Tripanosoma. En: Wilson WR, Sande MA editors. Current Diagnosis and Treatment in Infectious. Madrid. Lange Medical Books/Disease. Mc Graw-Hill Ediciones 2001: 842-53.

5. Alrajhi AA, Ibrahim EA, De Vol EB, Khairat M, Faris RM, Maguire JH. Fluconazole for the treatment of cutaneus leishmaniasis cused by

L.major. N Engl J Med 2002; 346: 891-5.

6. Braun J, Sieper J, Schulte KL, Thiel E, Janitschke K. Visceral leishmaniasis mimicking a flare of systemic lupus erythematosus. Clin Rheumatol 1991; 10: 445-8.

7. Fernández Guerrero ML, Aguado JM, Buzon L, Barros C, Montalbán C, Martín T, et al.Visceral leishmaniasis in inmunocompromised hosts. Am J Med 1987; 83: 1098-102.

8. Baixauli A, Rodríguez E, Campos C, Calvo Catalá J, García S. Enfermedad oportunista poco frecuente en enfermo con tratamiento inmunosupresor por artritis reumatoide. An Med Interna (Madrid) 2003; 20: 276-77. 